\title{
Interdisciplinary Team-Teaching Experience For A Computer And Nuclear Energy Course For Electrical And Computer Engineering Students
}

Charles Kim, Howard University, USA

Deborah Jackson, U.S. Nuclear Regulatory Commission, USA

Peter Keiller, Howard University, USA

\begin{abstract}
A new, interdisciplinary, team-taught course has been designed to educate students in Electrical and Computer Engineering (ECE) so that they can respond to global and urgent issues concerning computer control systems in nuclear power plants. This paper discusses our experience and assessment of the interdisciplinary computer and nuclear energy course, which was developed and offered primarily to ECE students at Howard University. A unique team-teaching model utilized with ECE professors and nuclear field experts was applied to teach the two diverse subjects: computer safety and nuclear energy. The survey result from the first offering of the course showed a very positive response from the majority of the students about the team-teaching method and the knowledge acquired on the two subjects.
\end{abstract}

Keywords: Computer Engineering; Nuclear Plant; Interdisciplinary; Team-Teaching

\section{INTRODUCTION}

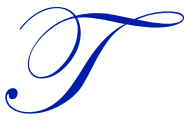

he curricula of Electrical and Computer Engineering (ECE) programs are challenged to equip ECE students to respond to the profession's adjustment toward globalization and global problems in climate changes, energy, and security which have world-wide implications and require modern engineering methods (Homfeck, 2010). In addition to the requirement of tackling global issues, ECE engineers are often asked to find technical solutions for issues of urgency and safety. One of these issues is the ever-increasing adoption of computer-based control in safety-critical systems and infrastructures, and its implication of safety and security of the plants which the systems are designed to operate and protect. A specific concern for computerized control systems is the operation of the nuclear power plant.

In the nuclear industry, digital instrumentation and control systems have developed tremendously during the past few decades, and the nuclear power generation community has been swiftly moving away from analog instrumentation towards computer technology. The rapid computerization in both new and older nuclear power plants by the phase-out of analog technology has resulted in computer systems becoming an important component of nuclear power plant design, operation and maintenance (NAP 2013). As a result, computer system reliability plays a crucial role in the safety of nuclear power plants. The reliability of computer based control systems has created a new set of concerns, since the failure of a single component, such as a processor or a network card, could disable major functions of the system and cripple the whole plant. Hence, reliability of software and safety against anomalies in nuclear power plant application continue to be of concern; therefore, software recovery and ways to develop systems that are tolerant to the "unknown" are continually sought. This new situation urgently requires a timely supply of capable ECE engineers who can deal with computer system reliability issues related to the nuclear power industry. These engineers need working knowledge of the practical aspects of safety against failures in computer control systems. To meet the need of educating ECE students in solving problems in digital and computer control systems in nuclear power plants, it is critical to establish foundational technical competence in computer 
safety and security as well as developing a technical understanding of nuclear power plant operation and safety issues. However, there is a practical challenge of teaching both computer safety and nuclear energy in an institution with no nuclear engineering program and hence no nuclear engineering or computer safety science faculty.

To achieve the goal of teaching ECE students at Howard University in both computer safety and nuclear energy, a new teaching model was conceived. A new course development project was proposed to the U. S. Nuclear Regulatory Commission (NRC), aiming to form an interdisciplinary team of teachers and to teach ECE students about computer safety and nuclear energy while at the same time diversifying the workforce and adding excitement for ECE students to the nuclear engineering field (NAP 2013). The proposal was granted and an interdisciplinary team was organized, comprised of the project investigators (2 ECE professors) to teach the computer side of safety, and nuclear fielded experts to teach the nuclear engineering side of safety. The course was offered primarily to ECE students of Howard University but opened also to other engineering majors.

This paper discusses the development and implementation of the team-teaching model, course content development, and course offering experience with assessment. In Chapter II, we briefly talk about the benefit of the team-teaching model along with how we formed the team. Chapter III focuses on the contents of the course of computer safety and nuclear energy subjects. We describe the experience of the first course offering and analyze the survey results of the course in Chapter IV. Then, Chapter V concludes the paper.

\section{INTERDISCIPLINARY TEACHING TEAM}

Team teaching is defined as a method of coordinated classroom instruction which involves a number of educators, professors only or professor and field experts, working together for a single course to bring a variety of different teaching styles and expertise to the course (Dong, 2011). More specifically, interdisciplinary team-teaching is a team-teaching method in which faculty members and/or field experts from various disciplines or departments work together to design, develop, and implement a single course of interdisciplinary contents (Summers, 1996). In interdisciplinary teaching, educators contribute their unique backgrounds, utilize their individual expertise, and promote integrated performance. Interdisciplinary teaching is known to be more effective in upper level survey courses than basic knowledge or problem intensive courses (Ivanitskaya, 2002). Interdisciplinary team-teaching has been applied in business-biology team teaching for environmental science and business students, and student learning gain was assessed, with the finding that the interdisciplinary experiment led to achievement of significant learning outcomes by changing student attitudes, expanding worldviews, and sharing diverse perspectives (Little, 2011).

In developing the interdisciplinary course of computer safety and nuclear energy, the motive for adopting the interdisciplinary team-teaching model came from two sides of the reality in ECE student instruction: First, the need to teach ECE students in the global issues of urgency and safety criticality in particularly nuclear industry in the area of computer control systems, and second, the lack of nuclear engineering/science faculty at Howard University. Therefore, the most viable option to meet the need and overcome the lack was to form a team of lecturers from two different fields to cover two very diverse subjects. The two ECE professors could teach the computer safety subjects and the nuclear field experts, once acquired and incorporated into the team, could teach the nuclear energy subjects. To find the nuclear experts, we used the geographical advantage of the university's location in the nation's capital with many government agencies and experts coming from all regions of the nation. The final outcome from this advantage resulted in collaboration with NRC. Through an NRC guest speaker series, NRC's volunteer field experts joined as interdisciplinary team-teaching members.

When a team is formed with professors and field experts, it can be argued that there is a concern because lectures given by field experts are largely unknown within academia and in the mindsets of students. However, this concern in our experience in the first offering of the course was unfounded. Instead, the collaborative course teaching by professors and field experts stimulated teamwork between the professors and the fielded experts, and students. The direct course assessment demonstrated that the interdisciplinary team-teaching with field experts was very well accepted by the students and increased students' enthusiasm and engagement in learning new subjects. Further, the interdisciplinary team-teaching produced unanticipated positive results among the graduate students: two ECE graduate students adopted problems related in nuclear energy as their thesis research topics. Moreover, the presence 
of more than one instructor in the classroom increased student-teacher interaction and student participation in the learning process as was also reported elsewhere (Leavitt, 2006) as a benefit of team-teaching. Details of the assessment of the course will further elaborate the interdisciplinary team-teaching experience after the course subject development is discussed in the next chapter.

\section{NEW COURSE DEVELOPMENT}

\section{A. Safe Computing Subjects}

For computing safety, the lecture contents were selected with emphasis on the concept of defense-in-depth and hardware/software diversity relevant to digital instrumentation and control (I\&C) of safety-critical infrastructure and processes. Specifically, the following subjects were selected and course materials were prepared by the two professors of Howard University.

Digital Instrumentation \&Control: A safety-critical plant or process has a central control room where operators collect, detect, analyze, monitor, and verify information from multiple indicators and alarms. The majority of I\&C systems in today's nuclear plants are beginning to apply advanced I\&C technology in all aspects of operation and maintenance.

Software Errors: Software used in safety-critical plants must ensure that required actions are taken and unnecessary trips are avoided. A number of software errors have been found in operating nuclear plant software, and it has been known that the failure due to software errors occurs as often as hardware failures and that software errors tend to be difficult to prevent because they may occur only under an unusual set of input conditions (Sommerville, 2011).

Computer Technology and Common Mode Failure: Computer control systems faces safety issues in that common mode failures may fail even redundant safety systems compromising safety functions (NAP 2013). Since software based I\&C is vulnerable especially to common-mode failures, in order to overcome single failures the system must be designed with redundancy in hardware and operating systems and must also deploy diversification strategies in application.

Defense-in-Depth and Diversity (D3): All safety activities are subject to layers of overlapping provisions so that a failure could be compensated for or corrected without causing harm to the entire system. The defense-in-depth concept, when properly applied, ensures that no single human or mechanical error leads to system failure and that even combination of multiple failures, which are only remotely possible, would not lead to a system accident. In the design diversity approach, multiple versions of software of different algorithms can be written for the same function. For hardware, processors and operating systems from completely different architectures and designs can be employed for the same function (Salewski, 2005).

Hardware Diversity Kit: This kit was built to give students the hands-on and practical aspects of the diversity strategy for safe computing. The hardware diversity kit is composed of an emergency event scenario generator and a set of diverse architectural hardware which individually responds to the scenario (Sonoiki, 2011). For coding each of the platforms, students are required to use different behavioral requirements for the same function for the scenario using different programming languages under different program development environments.

\section{B. Nuclear Energy Topics from Guest Speakers}

For the subject of nuclear energy, we arranged for volunteer field experts to lecture on the following topics.

Nuclear Overview: This topic covers the mission and the major regulatory activities in the areas of material, reactors, oversight, emergency responses, and new research.

Nuclear Reactor Concepts: Commercial nuclear power plant design categories are discussed covering primarily pressurized water reactors and boiling water reactors. 
Security and Safeguard of Nuclear Power Plant: Nuclear power plants must be both safe and secure so that using trained staff, equipment and other methods, the plant operation protects, not only the public and the environment but also the plant itself from intruders who wish to do harm.

Licensing Process: The steps and the level of details regarding the licensing are discussed for stable and predictable licensing process so that safety and environmental issues are resolved before authorizing construction and that timely and meaningful public participation is provided.

Power Generation: Design considerations and regulations are discussed for technical specifications and environmental qualification as well as maintenance rules. Worldwide industry trends are also discussed.

Digital System Safety and Cyber-Security: This subject is taught to ensure digital safety system reliability, availability, and integrity for non-malicious and malicious events. The topic discusses the history of digital system safety and cyber-security, provides an overview of the current cyber security program and digital system safety review, and describes regulatory developments regarding cyber-security.

Severe Accident Analysis: This topic compares design basis accidents and severe accidents in terms of accident severity as well as the station blackout and plant response.

New Rectors: This topic discusses the new, small modular reactors with specific features and safety systems.

\section{OFFERING EXPERIENCE}

The new course, officially numbered and titled as "EECE499 Computers and Nuclear Energy" in ECE at Howard University, was offered for the first time in fall 2011, open primarily to ECE students, both undergraduate and graduate, but also to other engineering majors. Each week, the two subjects were lectured in sequence, and the details of the lectures were available from the website of the project at http://www.mwftr.com/NuclearSafety.html. In the last week of the semester, two separate surveys were conducted respectively for the students and the guest speakers. The survey forms were adopted from a course survey form designed by a Howard University professor in the Education Department for a Mobile Studio class offered to electrical and computer engineering students (Kim, 2008).

The focus of the student survey was to measure (a) students' perception of the interdisciplinary course and the teamteaching approach and (b) students' level of satisfaction of knowledge gained from the course. On the other hand, the emphasis of the field expert guest speaker survey was placed on the measurement of the satisfaction in (a) the class logistics and (b) the students' response and interaction with the field experts.

For the student survey, out of 28 students enrolled, 26 students completed the student survey, comprising 16 ECE undergraduate students, 3 Chemical Engineering undergraduate students, and 7 ECE graduate students. In gender and level partition, they were: $31 \%$ female undergraduate, $42 \%$ male undergraduate, and $27 \%$ male graduate students. Overall, the students expressed very positive responses concerning the course. They rated the course quite favorably in terms of increasing their (a) understanding in computer mistakes and errors (b) understanding nuclear energy and safety, (c) understanding the use of computers in nuclear power, and (d) interest in safety-critical computer systems. Overall, the course met their expectation.

For the guest speaker survey, only 6 participated out of 15 . Guest speakers were also satisfied with their experience with the interdisciplinary team teaching of the diverse two subjects in logistics and student interaction. The insufficient number of responses for the guest speaker survey could not provide general conclusions, nevertheless it provided some useful observations. Details of the surveys are discussed below.

\section{A. Student Survey and Assessment}

For the general perception about the Interdisciplinary course, students were asked to rate, for the items shown below, how much the combined teaching by Howard professors (on computer topics) and the field expert guest 
speakers (on nuclear energy) increased their leaning. The rating scale was given as: score of 1 for "Strongly Disagree"; 2, "Disagree"; 3 "Neutral"; 4, "Agree"; and 5, "Strongly Agree."
a. Understanding in computer mistakes/errors
b. Understanding in nuclear energy and safety
c. Understanding the use of computers in nuclear area
d. Interest in safety-critical computer systems
e. Interest in nuclear energy and safety
f. Interest in employment in computer safety field
g. Interest in employment in nuclear energy field
h. Overall, the course met my expectation

The mean score of the ratings for the above items are tabulated in Table 1. From the table, it can be said that students learned enough of the interdisciplinary subjects and were stimulated by the subject contents. ECE students were as much stimulated to seek their employment mainly in the computer safety field as were Chemical Engineering students in the nuclear energy field.

Table 1. Student's General Perception on the Course

\begin{tabular}{l|c}
\hline \multicolumn{1}{c|}{ Items } & Mean \\
\hline a. Understanding in computer mistakes/error & 4.54 \\
\hline b. Understanding in nuclear energy and safety & 4.54 \\
\hline c. Understanding the use of computers in nuclear area & 4.38 \\
\hline d. Interest in safety-critical computer systems & 4.46 \\
\hline e. Interest in nuclear energy and safety & 4.15 \\
\hline f. Interest in employment in computer safety field & 4.11 \\
\hline g. Interest in employment in nuclear energy field & 3.96 \\
\hline h. Overall, the course met my expectation & 4.27 \\
\hline
\end{tabular}

For the student satisfaction in the course, the students were asked to rate their satisfaction level on the following items using the same rating scales as in the previous question.
a. Content and presentation on Safe Computing
b. Amount of knowledge gained on Safe Computing
c. Content and presentation on Nuclear Energy
d. Amount of knowledge gained on Nuclear Energy

The mean scores for the above question items are indicated in Table 2. The table shows that the students were highly satisfied with the contents and their knowledge gain in both safety computing and nuclear energy, but with a slightly higher degree in the former. It is apparent that students accepted the interdisciplinary team teaching, learned from both sets of instructors, and were satisfied with the contents of the team-taught course.

Table 2. Student Satisfaction on the Course

\begin{tabular}{l|c}
\hline \multicolumn{1}{c|}{ Items } & Mean \\
\hline a. Content and presentation on safe computing & 4.46 \\
\hline b. Amount of knowledge gained on safe computing & 4.50 \\
\hline c. Content and presentation on Nuclear Energy & 4.15 \\
\hline d. Amount of knowledge gained on Nuclear Energy & 4.34 \\
\hline
\end{tabular}

To know more of the students' attitudes on the course, the following five open-end questions/comments were given to the students:

- What were the most valuable lessons/knowledge/understanding you gained?

- What changes/improvement in the "Computer" area, do you want to see in the future offering of the course? 
- What changes/improvement in the "Nuclear Energy" area, do you want to see in the future offering of the course?

- What changes/improvement in the course in general do you want to see in the future offering of the course?

- Any additional comments about the course.

The analysis of these open questions revealed that students highly viewed their learning in safety in computer system, defense in-depth and design diversity, and nuclear concepts. However, they expressed their desires and wants. In the "computer" side of the course, they requested more practical materials and activities on top of the fundamentals and principles. In the "nuclear" side, the students requested nuclear site visits and additional technology-oriented lectures in addition to the regulation-focused ones.

\section{B. Guest Speaker Survey and Assessment}

This survey was conducted in December 2011 after the semester was over. Due to the heavy schedule and travel of many expert guest speakers, this survey had only six participants out of 15 . There were two questions for the guest speakers: logistics and satisfaction.

For the class logistic, the guest speakers were asked to rate their satisfaction on the following items with the scale of: 5-Very Satisfied, 4- Satisfied, 3- Neutral, 2-Dissatisfied, 1-Very Dissatisfied:

a. Your experience as a guest speaker

b. Communication and arrangement of the classroom for presentation

c. Adequacy of support and service for presentation

d. Adequacy of technical \& multimedia resources for presentation

e. Adequacy of the length of the time given for the presentation

As summarized in Table 3, the guest speakers had very positive experiences in all of the items.

Table 3. Guest Speakers Response to the Class Logistics

\begin{tabular}{l|c}
\hline \multicolumn{1}{c}{ Items } & Mean \\
\hline a. Your experience as a guest speaker & 4.83 \\
\hline b. Communication and arrangement of the classroom for presentation & 4.50 \\
\hline c. Adequacy of support and service for presentation & 4.67 \\
\hline d. Adequacy of technical \& multimedia resources for presentation & 4.67 \\
\hline e. Adequacy of the length of the time given for the presentation & 4.17 \\
\hline
\end{tabular}

Regarding how students responded to and interacted with them, the following questions were asked of the guest speakers for their ratings:

a. Interaction with students in and outside classroom

b. Student response and understanding

c. Appropriateness of the subject and level of difficulties to students

d. Motivation of student's interest in nuclear industry

As displayed in Table 4, the speakers rated the experiences of this course as quite favorable in interaction with students in and outside the classroom, student response and understanding, and motivation of students' interests in nuclear industry.

\begin{tabular}{lc}
\multicolumn{1}{c}{ Table 4. Guest Speaker's Response to Students } & Mean \\
\hline \multicolumn{1}{c}{ Items } & 4.17 \\
\hline Interaction with students in and outside classroom & 4.50 \\
\hline Student response and understanding & 4.33 \\
\hline Appropriateness of the subject and level of difficulties to students & 4.17 \\
\hline Motivation of student's interest in Nuclear industry & \\
\hline
\end{tabular}


Similar to the students, the expert guest speakers were asked to respond to open-ended questions concerning their part:

- Do you have any suggestion for improvement?

- Are there any other subjects you think would be beneficial for the students of "Computer and Nuclear Energy?"

For course improvement, the guest speakers pointed out the linking of two different subjects and suggested that students look at their ECE studies with regards to the nuclear energy application and ask questions of the speaker to augment the connection. They also suggested a tour at local nuclear power plant. For the new subjects that would be beneficial to the engineering students, they suggested the following: (a) a lecture on the development of regulation in the areas of computer control systems and related topics, (b) virtual learning tools of nuclear power plants, and (c) a basic course in thermal sciences.

\section{Additional Benefit - Research Ideas}

Two graduate students who took the course decided to choose their thesis subjects in nuclear safety areas. Both students have worked on emergency diesel generator failures but in slightly different focuses: one on the demand failure and the other on false start. A student in the demand failure subject has co-authored an article on the subject and presented it in an international system safety conference (Kim, 2012).

\section{Course Revision BASED on Assessment Data}

The result of the survey raised the need for course revision. There are two items to be adopted for the next offering of the course; the first one came from the students' wishes and the second one from the guest speakers' suggestions. To meet the first need for more practical and hands-on experience in safe computing in software and hardware, we are currently conducting tasks on (a) bringing to the class actual erroneous software codes and programs and asking students to correct them and (b) allocating more time and frequency in hardware diversity kit sessions. To accommodate the suggestions from the guest speakers for basic nuclear physics subjects, the authors are working together to collect and explore virtual teaching tools and open courses, and to expand the pool of the field expert speakers.

\section{CONCLUSIONS}

This paper described an experience of developing an interdisciplinary course in computers safety and nuclear energy with a team of professors and field experts. The course was taught to ECE students (mostly undergraduate) at Howard University in order for them to effectively respond to global and urgent concerns on the safety issues related to computer control systems in nuclear power plants. The course was offered and team taught for the first time in the fall 2011 semester. The majority of the students agreed that the course met their expectation and gained knowledge in the interdisciplinary subjects. The field experts also expressed their satisfaction in team teaching with the classroom logistics and interaction with the students. The course is currently in the revision process to meet the students' wishes and the speakers' suggestions for more hands-on and virtual learning environments. This interdisciplinary course at Howard University, with continual progress, would meet the demand for teaching and stimulating ECE students to solve problems of global implications and urgency and eventually help diversify the workforce in the field of computers and nuclear safety.

\section{ACKNOWLEDGMENTS}

The authors of Howard University acknowledge the financial support of the U. S. NRC through the grant: NRC-2710-1123. 


\section{AUTHOR BIOGRAPHIES}

Charles Kim is a professor in Electrical Engineering and Computer Science at Howard University. He received a Ph.D. degree in electrical engineering from Texas A\&M University (College Station, Texas) in 1989. He had held teaching and research positions first at Texas A\&M University and later at the University of Suwon before joining Howard University in 1999. Dr. Kim's research includes failure detection, location, and anticipation, and cyberphysical system safety and security analysis in safety critical systems in automotive, energy, aerospace, and nuclear industries. Dr. Kim is a senior member of IEEE and the chair of the IEEE Education Society chapter in the Washington-Baltimore section. Corresponding author: Charles Kim (ckim@howard.edu)

Deborah A. Jackson is a member of the Senior Executive Service at the U.S. Nuclear Regulatory Commission (NRC). Currently she is responsible for advanced reactor projects and activities involving the licensing of new and advanced reactor power plants. She has over thirty years of experience in design, construction, operation, inspection and maintenance of commercial nuclear power plants and fuel fabrication facilities. She has represented the NRC at numerous national and international meetings and conferences to include International Atomic Energy Agency (IAEA), International Council on Nuclear Engineering (ICONE), American Society of Mechanical Engineers (ASME) and Organization for Economic Co-operation and Development/Nuclear Energy Agency (OECD/NEA). Throughout her professional career she has been involved in numerous volunteer and civic activities. She is a mentor to many, providing principled feedback and advice on the transition from college to work, dealing with stereotypes, interviewing, interpersonal skills, and the importance of continued professional development. Prior to joining NRC, Ms. Jackson worked in the commercial nuclear power industry as a design engineer, construction inspector and auditor for plants in the US, Europe and South Africa. Ms. Jackson received her Bachelor's degree in Mechanical Engineering from Howard University.

Peter A. Keiller received his B.S. in Civil Engineering and his M.S.C.S. in Computer Science from Howard University (HU) in 1972 and 1974 respectively. He also received the M.S. degree and the Applied Scientist degree in Operations Research, and the D.Sc. degree in Engineering Management from the George Washington University (GWU) in 1982, 1983, and 1996 respectively. Between 1974-1994 he was employed at the IBM Federal Systems Division, Maryland. He is currently an Associate Professor of Electrical Engineering and Computer Science at Howard University, Washington D.C. His technical contributions have been largely focused on: Dependable Systems; Data Mining; and Systems Engineering.

\section{REFERENCES}

Dong, Y. et al. (2011). A Methodology for Team Teaching with Field Experts. International Journal of Process Education, 3(1), No.1, 43-50.

Homfeck, W. et al. (2010). Educating Electrical and Computer Engineering Majors for a Global Environment. ASEE MidAtlantic Conference, Easton, PA.

Ivanitskaya, L. et al. (2002). Interdisciplinary Learning: Process and Outcomes. Innovative Higher Education, Vol. 27, No. 2, Winter 2002.

Kim, C. et al (2008). Mobile Studio Experience of Experiential Learning in Electrical Engineering Class. Proceedings of ASEE 2008 Conference.

Kim, C. et al (2012). Analysis of an Emergency Diesel Generator Failure Incident in Nuclear Power Plants. 31st International System Safety Conference.

Leavitt, M. (2006). Team teaching: Benefits and Challenges. Fall 2006 Newsletter, 16(1), 1-3 , Center of Teaching and Learning. Stanford University, Palo Alto, CA.

Little, A., \& Anne Hoel, A. (2011), Interdisciplinary Team Teaching: An Effective Method to Transform Student Attitudes. The Journal of Effective Teaching, 11(1), 36-44.

NAP (2013). Digital Instrumentation and Control Systems in Nuclear Power Plants - Safety and reliability Issues, National Research Council, National Academic Press, Washington, DC.

Salewski, F. et al (2005). Diverse Hardware Platforms in Embedded Systems Lab Courses: A Way to Teach the Differences. ACM SIGBED Review, 2 (4) , 70-74.

Sommerville, I. (2011). Software Engineering, $9^{\text {th }}$ Edition, Pearson.

Sonoiki, O. \& Kim, C. (2011). Development of a Hardware Diversity Training Kit for Nuclear Industry. ANS 2011 Student Conference, Atlanta, GA.

Summers, D., \& Bohlen, G. (1996). Team Teaching an Interdisciplinary course: Lessons Learned. ASEE Annual Conference Proceedings. 